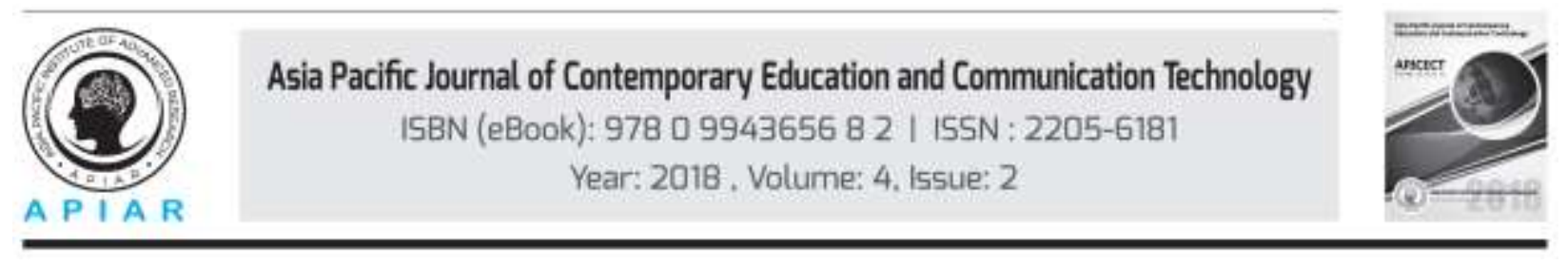

\title{
REDUCTION OF DISCRIMINATION BETWEEN RURAL AND URBAN PRIMARY EDUCATION IN BANGLADESH
}

\author{
Mashraky Mustary \\ Sophia University, Tokyo, Japan \\ Corresponding Email: mitu.shona@gmail.com
}

\begin{abstract}
Education acts as a critical indicator of prosperity, progress, and success in every society. There are cases; however, when the main goal of education is not achieved due to discrimination. The aim of this paper is to address these cases, specifically in Bangladesh. The findings of this research being the determination of the main causes for the disparity between urban and rural primary schools, the challenges, development and success of education, and the changes over time. Equal primary education is a significant necessity to any citizen of a country. The affiliation between poverty and education is spherical; the lack of equality in primary education forces poor families to engage in less productive pursuits, which results in more misery. Nevertheless, discrimination between the poor and the rich leads to a low investment in education.

In Bangladesh, inequality in education has appeared as a significant hindrance to achieving universally recognized education. In the recent past, the poor were denied the right to quality education; only the children from wealthy households had access to quality education. The discrepancies in primary school education exist in the areas of primary education, locality, and gender, keeping in mind the economic status of the people of Bangladesh. The primary cause of the disparities was a failure of the government to implement strategies and allocate adequate resources for primary education. Additionally, discrimination in the urban-rural learning settings is based on the high fees being charged by urban schools. Operational education causes are also part of the inequality in primary education. The government of Bangladesh has taken some measures to change this, while governmental and non-governmental organizations have helped to reduce the inequality gap in primary education. For example, the government has introduced a scheme which aims at improving enrolments in primary schools in rural areas. A study by Ahmed (2005) noted that this project has achieved a 14\% improvement in admission. Secondly, the government is attempting to fight against corruption. The number of cases related to stealing funds budgeted for the poor has decreased significantly. Additionally, the NGOs, along with the GOs, have played a significant role in ensuring the enrolment of the girl children in schools. They have empowered women to end the mentality that females are born solely to run a household. These actions and strategy will be discussed in this paper.
\end{abstract}

Key Words: Rural education, Urban education, Bangladesh. 


\subsection{Introduction}

The 1990 legislation titled Bangladesh Primary Education made school attendance compulsory for all children between the ages of six and ten. Further, the United Nations Millennium Development Goals, to which Bangladesh ascribes, require that the government provide quality and affordable education for all the children in their country. The key word here is "all." However, despite government efforts to standardize education and make it affordable for all, its citizens, the challenge of discrimination in learning institutions has slowed down this movement. Learners from the rural areas are mainly the victims of this discrimination, which is steered by urban pupils. It is shocking to discover that the majority of these children opt to stay out of school rather than face this challenge. Data from past research show that $74 \%$ of learners who are subjected to any form of discrimination will drop out of lower secondary (Abates et al, 2010. These findings demonstrate that much action needs to be taken to ensure that the government goals were met.

This research paper seeks to address these concerns by answering the following research questions that is achieved by way of statistics.

I. How has the rural/urban distance contributed to this discrimination? Has this situation changed over the past ten years and what are the subsequent effects?

II. How does genealogy affect Bangladesh's recovery from this situation? Does the profession of a given parent affect the child's performance in school or has it contributed to the discrimination?

III. Have there been any attempts by concerned stakeholders- that is, teachers, parents and the government - to minimize these problems? Are these actions sufficient or does work still need to be done?

IV. What can be learned from a comparative analysis regarding the advantages or disadvantages that children in these different settings have compared to their counterparts?

V. The overall findings shall also be discussed in detail, and recommendations are given as well.

The methodology used in the research and the literature review will be described in sections two and three, followed by a report that will expound upon the issue of discrimination. Conclusions based on these factors will complete the paper. The study will review the ways that discrimination by origin has affected the education system, with the most important aspect being possible methods of reducing this situation. Quality of education and equal access are the main parameters used to determine the basis of discrimination. Additionally, the paper will address the role played by poverty level, occupation and access to information in promoting this discrimination in primary education.

\section{2.o Methodology}

The objective of this study is to explore the issue of discrimination of the rural children in Bangladesh when attempting to access education. To determine this, the study used a mixed methods approach, coupled with interviews of relevant stakeholders, including teachers, pupils, and parents. Statistics obtained from the observations of the researcher was also included. An extended stay in both rural and urban settings gave the author an opportunity to gain the experience necessary to make deductive conclusions. Analyzing data from various secondary sources provided an additional perspective on the situation. The choice of these methods was greatly influenced by the need to have an in-depth analysis of all the schools found in Bangladesh, from state-funded to private and religious schools. 
The research took place over a period of six months, from May to November, 2017 in both rural and urban settings of Bangladesh. During this time, the environment of the education subdistricts, or the Upazila, is defined as a unique system of education in the country. A good rapport was created with the teachers and the pupils, and this facilitated many informal visits to various schools, thereby gaining information through observations of actual behaviors. Although classroom participation was impossible as it caused commotion, the study sample proved to be very cooperative. However, some challenges were faced in attempting to obtain reliable data, especially from the rural areas, since most of the schools did not maintain up-to-date data on enrollment and drop out cases. Also, the issue of a language barrier hindered my study, although it was partially resolved by having an assistant researcher who also acted as a translator (Hmad, 2007).

\section{3.o Literature Review}

While analyzing the issue of discrimination in the education sector, the first step is defining the term "discrimination." While scholars in different settings have framed it differently, the most outstanding aspect is excluding or disadvantaging a section of the population, generally the minority, by inbuilt factors that are beyond them. The most common foundations of discrimination have been gender, skin color, education level of one's parents, social status, and religion. Their exclusion makes victims feel unwanted and also lowers their self-esteem. Additionally, the targeted people, in this case students, develop defense mechanisms by missing classes or dropping out of school totally, and this worsens the situation. The primary form of exclusion of these children has been the physical inaccessibility of learning institutions.

Bangladesh is a middle-class Asian country with a population of about 164 million people, of which $90 \%$ have had access to primary education. The government expends $2.4 \%$ of the GDP on education, which ranks it among the nations who view education as a low priority (Bangladesh Bureau of Statistics, 2011). The majority of school expenses are paid by the parents, an issue which was explicitly addressed at the 1990 World Conference on Education for All held in Jomtien. Here, Thailand expressed concerns about the efforts made by the Bangladeshi Government. As a result, both the government and the international donors began establishing schools to ensure that all children would have access to education. Enrollment has risen to 90\% as a result of these actions. However, a corresponding increase in the quality of education did not accompany this and about half of the children dropped out. This happened despite the poverty levels dropping from 57\% in the 1990's to 36\% in 2015 (World Bank, 2015b).

\subsection{Findings}

After extensive surveys and research, many causes of this disparity were highlighted which formed the basis for determining solutions. Firstly, the causes of discrimination will be explored. The author was specifically fussing on three schools in the region and a total of twelve individuals was taken as the sample size. These individuals included teachers, parents and the pupils. The main response was that there was discrimination in the primary schools and as a result many Bangladesh students drop out of school. The survey was conclusive and the evidence obtained can be used to make the following conclusions.

\subsection{Causes of Discrimination}

The following were identified as the leading causes of the discrimination currently experienced between rural and urban primary level pupils in Bangladesh.

\subsubsection{Disparity of Literacy Rate by Locality}

A recent study by National Education Policy indicates that the literacy rates in Bangladesh's rural and urban centers are 53\% and 70\%, respectively. This disparity has shown a constant increase of $1.35 \%$ annually (NEP, 2014). This implies that, in the next ten years, the number of 
children being enrolled for studies in urban areas will be twice as high as those enrolled in rural areas. It is disturbing to notice further that the disparity is not backed up by population disparities. Although the number of people living in towns and cities is greater than those living in the villages, the proportionate figure of those in schools shows the difference. In towns for example, $98 \%$ of children born in town are enrolled in schools unlike the $88 \%$ that are enrolled in villages (Hmad, 2007). It is clear that a higher value is placed on education in the cities than in the villages.

\subsubsection{Disparity in Infrastructure and Social Amenities}

Cities and towns have better facilities for learning than the villages, since people can afford to construct better classrooms and install better services which have the necessary workforce and skills available. All the experts seem to reside in populated areas, and as a result, development is inevitable there. Consequently, this is being done at the expense of poor villagers. The pupils in the rural areas will thus be disadvantaged, but will have to pass the same exams; they will most probably lose to their counterparts in the urban areas. It has already been statistically established that children in the towns perform better in school than those in the rural areas. The average performance of a child in town is $76 \%$ while those in villages is $6 \%$ (BBS, 2011).

\subsubsection{Differences in the Level of Exposure}

Many of the concepts taught in schools remain a mystery to most learners. However, it is even more confusing for a child in the interior parts of Bangladesh to understand the concepts of information technology or sophisticated locomotives. They only have a mental image of these, based the explanations they received from their teachers or parents (Ministry of Planning, 2006). As a result, their understanding is lower than that of their competitors in the cities, who have not only seen a majority of these things, but have also had an opportunity to use them. This remains a primary cause of the discrimination, as all these children will be subjected to the same tests and exams without any affirmative action.

\subsubsection{Poverty Levels}

Children of poor households, who are mostly found in the villages, are disadvantaged when it comes to education access. Since parents are required to pay for the education of their children, this is difficult to manage after providing for the family's basic needs. Eventually, the children do not enroll in any learning institution, and if they do, they are not able to finish. This can be proved further by a survey that was conducted in a remote village of Bangladesh, where it was discovered that approximately $96 \%$ of the poor drop out of school. Currently, the percentage of school admission for the rich in towns and the poor in villages is $96 \%$ and $74 \%$, respectively. This disparity is increasing annually at a rate of $1.28 \%$. Unless the government subsidizes the cost of education, the entire population of rural areas will be illiterate (Asu and Asad 2010).

\subsubsection{Student-Teacher Ratio}

The National Education Policy of 2010 requires that the ratio of teacher to students is 1:30. The number has nearly been achieved in the urban areas, with the ratioat1:32 as of last year (NEP 2010). However, the number is increasing in the rural areas, especially since teachers are not willing to work in these places. Most of the teachers posted to the rural areas ask for a transfer within their first three years there. As a result, pupils in the villages lack quality education as their teachers are overstretched and cannot meet the expected demands of the job. This is yet another aspect of discrimination against the village children, who had no choice in determining $m$ their place of birth and do not have any power to change the situation. 


\subsubsection{Private Tutoring}

Private tutoring is common in Bangladesh, where students attend studies past the usual stipulated school day. Such arrangements are usually made between the parents and the teachers, and the parents are expected to pay the entire bill. These arrangements are possible in urban areas, but in rural areas, it rarely happens because the children are engaged in other activities, such as work. The result is that the village children do not experience the same contact hours, although they will take the same standard exam.

\subsubsection{Corruption and Women Empowerment}

It was established that the cases of corruption in the education sector has had an effect on the access of education. Corruption is spread and it mostly affects children in the rural because people there are not so much conversant with their rights (Khandker, 2009). The people here do not know the allocations that the government has granted them and even when lost no disclosure will be done. Also, the women particularly those in the villages do not have equal chances to accessing education. Some of the girls miss schools during their menses while others are denied the opportunity to be in schools and are forced into early marriages (Nath, 2007).

\subsection{Methods of Reducing the Discrimination}

The above cases illustrate how the children in rural areas are disadvantaged. It is clear that these pupils cannot fairly compete with their counterparts in towns. The mastery of the content is different, the level of understanding is different and learning environment is also different. Therefore, the following measures maybe taken to minimize the current discrimination. It is the responsibility of any given government to ensure equality to all its citizens, and as such, the government of Bangladesh should be in the forefront of providing equality. No child should be disadvantaged by their origin, race or status of their parents.

\subsubsection{Poverty Eradication in Rural Areas}

The government should empower its citizens, especially the marginalized communities in the rural areas of Bangladesh. These people cannot afford three meals a day, let alone education for their children. The government should consider providing programs to create incomegenerating ventures in the villages. Once villagers can provide for their basic needs, they will devote themselves to educating their children. Additionally, empowering people through poverty eradication exposes them to diverse challenges, which will initiate the desire to learn and to acquire the skills necessary to face these challenges (Ministry of Planning. 2006).

\subsubsection{Meeting Part of the Schooling Expenditure}

Despite the fact that the government initiated "free" primary education, most of the expenses are paid by the parents, which put needy families in jeopardy. Parents have to pay tuition, as well as provide school supplies, such as books, pens, uniforms, bags and other stationery. Additionally, an exam fee is also paid by the parent three times a year, plus the additional costs of sending the children in schools as expensed in the transportation and food costs. All these costs are a burden to the low-income families, especially in the rural areas (Campaign for Popular Education, 2009). Education for its citizen should be entirely free, since the government will be creating a better workforce.

\subsubsection{Dealing with the Seasonality Problem}

Rural residents are reported to be vulnerable to Mongo, a seasonal variation of hunger, national calamities and seasonal unemployment. Those affected by this problem often migrate in search of better opportunities. As a result, the children are taken out of school. Unless the government provides formal employment and a reliable method of dealing with the catastrophic causes of their migration, the children will remain affected by their parents' movements. At the same 
time, the parents who force their children out of school to work in the fields during the busiest harvesting seasons should be held responsible and punished accordingly or the school calendar can be changed by the government such that during the harvesting seasons the children are in their holiday (Khandker, 2009).

\subsubsection{Revising the Curriculum}

The textbooks and supplementary materials used in schools are a major concern, since they are not only ancient and unreliable, but also lack the interest that children should find in books. To capture the attention of children and motivate their learning, the government should consider revising the curriculum. The teachers should also be retrained to create a good learning environment that will attract and keep more pupils in the schools (Us-Sabur and Ahmed 2010).

\subsubsection{De-centralizing Education Management}

Education is centrally managed in Bangladesh, and this is not an efficient way of addressing the challenge of discrimination by locality. The central managers may not know the challenges that rural pupils are facing, so it is necessary to have a manager who will understand fully. At the same time, managers should have increased accountability to ensure that they perform the duties allocated to them, which will discourage a waste of taxpayers' money. This will also ensure that the quality of education is standardized (Nath, 2007).

\section{Conclusion}

This study not only describes the socio-economic factors influencing discrimination in primary education, but also recommends priorities to solve the problem. Unequal opportunities clearly exist between the rural and urban pupils in Bangladesh. Policies should be instituted to ensure that no child is disadvantaged based on their area of origin. Failure to implement the proposed plans will continue to place Bangladesh among the countries with the least support for education. The implementation of these policies clearly calls for collective responsibility; it is not just the role of the government, but also the teachers, parents and larger society. Additionally, achievement of the Millennium Development Goals calls for a total commitment to the education sector in order to ensure quality, affordable education. 


\section{References}

i. $\quad$ Abates, R., Hossain, A., \& Lewin, K., 2010. School Drops Out in Bangladesh: New Insights from Longitudinal Evidence. CREATE Pathways to Access Research Monograph \#49.[Online] Available at: http://www.create-rpc.org/pdf_documents/PTA49.pdf [accessed 30 May 2011].

ii. Asu, F. K., \& Asad, A. U. Z., 2010.Education Policy: Problems and Prospects of EFA in Bangladesh [Online] Available at: http://www.bdeduarticle.com/educationpolicy/37uncatagorized/157-problems-and-prospects-of-efa-in-bangladesh (Accessed 10 September 2011).

iii. Bangladesh Bureau of Statistics (BBS), 2011.Population and Housing Census 2011, Preliminary Results. [Online] Available at: http://www.bbs.gov.bd/WebTestApplication/userfiles/Image/BBS/PHC2011Preliminar y\%20Result.pdf [accessed 1 December 2011].

iv. Campaign for Popular Education, 2009.State of Primary Education in Bangladesh: Progress Made, Challenges Remained. Bangladesh: Campaign for Popular Education. [Online] Available at:http://www.books.google.com/.../State_of_primary_education_in_Bangladesh.ht [Accessed1 September 2011].

v. General Economics Division, Planning Commission, Government of the People's Republic of Bangladesh \& UNDP Bangladesh, 2011.A Situation Analysis Report on Education (MDG 2) Bangladesh: A Baseline for Needs Assessment and Costing Bangladesh. [Online] Available at: http://www.undp.org.bd/projects/.../Situation\%20analysis_education.pdf [Accessed 5 September 2011].

vi. Hmad, Q.K. et al., 2007.Education Watch 2006: Financing Primary and Secondary Education in Bangladesh. Campaign for Popular Education (CAMPE), Bangladesh.[Online] Available at: http://www.campebd.org/download/EW2006FullReportEnglish.pdf [Accessed 20 May 2011].

vii. Khandker, S., 2009.Poverty and Income Seasonality in Bangladesh, World Bank Policy Research Working Paper 4923.[Online] Available at: http://library1.nida.ac.th/worldbankf/fulltext/wpso4923.pdf [Accessed 30 May 2011].

viii. Ministry of Planning, 2006.Preliminary Report on the Household Income and Expenditure Survey (HIES) 2005. Dhaka: Bangladesh Bureau of Statistics (BBS), Planning Division, and Government of the People's Republic of Bangladesh.

ix. Nath, S.R., 2007.Remunerated Supplementary Tutoring in out-of-school Study in Rural Bangladesh. BRAC Research Report, BRAC Research \& Evaluation Division.[Online] Available at: http://www.bracresearch.org/reports/remunerated_supplementary.pdf [Accessed 10 July 2011].

x. Us-Sabur, Z. and Ahmed, M., 2010.Debating Diversity in Provision of Universal Primary Education in Bangladesh. CREATE Pathways to Access Research Monograph \#34.[Online] Available at: http://www.create-rpc.org/pdf_documents/PTA34.pdf [Accessed 10 June 2011].

xi. World Bank, 2011. Bangladesh Data. [Online] Available at: http://data.worldbank.org/country/bangladesh. [Accessed 20 December 2011]. 